EPiC Series in Engineering
Volume 3, 2018, Pages 1104-1112
HIC 2018. 13th International
Conference on Hydroinformatics

\title{
A Teaching Experiment Using a Serious Game for WDNs Sizing
}

\author{
Daniele B. Laucelli ${ }^{*}$, Luigi Berardi ${ }^{1}$, Antonietta Simone ${ }^{1}$ and Orazio \\ Giustolisi ${ }^{1}$ \\ ${ }^{1}$ Politecnico di Bari, Via E. Orabona 4, 70125 Bari, Italy \\ danielebiagio.laucelli@poliba.it, luigi.berardi@poliba.it, \\ antonietta.simonelpoliba.it, orazio.giustolisiepoliba.it
}

\begin{abstract}
A new playful interface allowing a more intuitive understanding of real-life problems is the Serious Gaming, which combines video game and utility functions addressed to problems other than the mere entertainment. The use of Serious Gaming allows having fun while favoring the learning process related to specific technical fields. This paper presents the results of using Serious Gaming within a university classroom of 26 students to solve an engineering problem, i.e. the pipe sizing of several water distribution networks. It relates to five benchmark water distribution networks, and students were asked to find the optimal value of pipe diameters to match minimum capital cost of pipes and good average pressure. Therefore, the players/students can be seen as decision makers, from a real-life standpoint. The paper has multiple aims, such as investigating the gaming approach usefulness in consolidating/learning the main concepts of network hydraulics and bringing users closer to real-life complexity of engineering problems where different technical aspects must be considered at the same time.
\end{abstract}

\section{Introduction}

Serious Games are games designed for a primary purpose other than pure entertainment. They are an educational tool aiming at developing skills or teaching formal contents through a playful interface. Two main points characterize a Serious Game:

- it combines video game and one or several utility functions: broadcasting a message, providing training, facilitating the exchange of data;

\footnotetext{
${ }^{*}$ Corresponding author: danielebiagio.laucelli@poliba.it
} 
- it is addressed to areas other than the mere entertainment: defense, training, education, health, commerce, communication, city planning, engineering, etc.

Exist traces of the use of the term "Serious Gaming" back to the Renaissance, but the first use of the Serious Game oxymoron with a meaning close to its current use seems to be in (Abt, 1970), which proposed games for training and education of military officers during the Cold War conflict on a worldwide scale. The twenty-first century offered, and continues to propose, many Serious Games applications in various areas, such as healthcare (Brown, et al., 1997), sports (Harfield, 2008), education (de Freitas, 2006), politics (Jansiewicz, 1973; Sawyer \& Rejeski, 2002; Kahn \& Perez, 2009; Jansiewicz, 2011), climate changes (Leroy \& Saulnier, 2013), the company management (Schrage, 1999), arts (Graham, 1996), etc.

The aim is providing solutions to real problems (through play) representing at once a real source of satisfaction for player. It has been shown, in fact, that the games tend to always push beyond the limit, with ever-greater commitment and determination. The payout would be twofold: (i) surpassing levels with visible results that can be connected to our efforts (win the game); and (ii) contribute in solving real problems (win in the reality). These aspects, together with advances in computer technology and changes that are affecting the world of work and training, have favored the rapid increasing of serious gaming.

Serious Games can be seen as educational tools, to be applied both at school and within many fields of professional activities, among which the water distribution network (WDN) design and management is comprised.

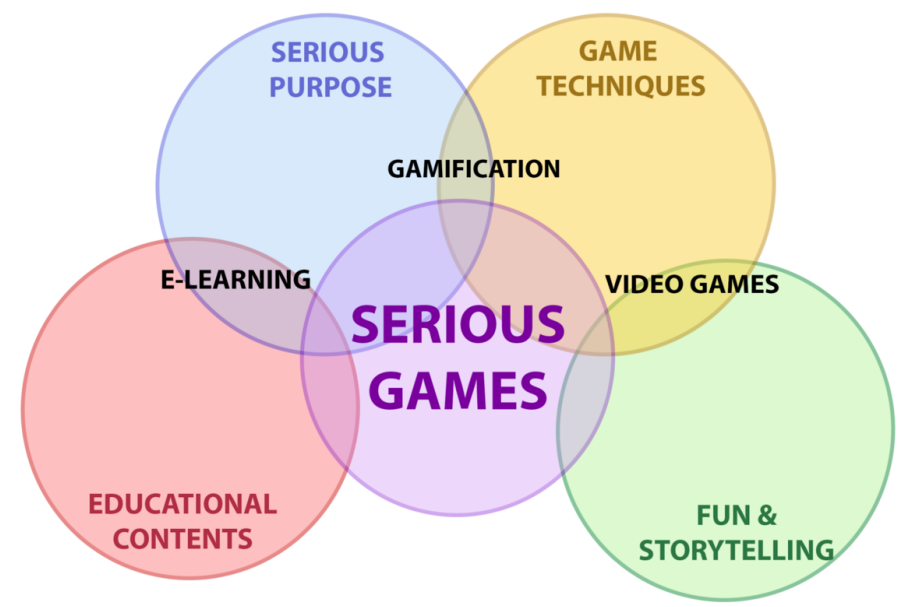

Figure 1. Venn's diagram of Serious Gaming aims and contents

By using complex models with real data via simple and playful game interface adapts to everybody (students, researchers, stakeholders, citizen, etc.) (Leroy \& Saulnier, 2013), promotes active collaboration between researchers and stakeholders.

Several serious games have been proposed to reproduce water systems issues with different rules. Based on the existing literature, for example, Serious Games concern water resource management (Morley, et al., 2017; Wang \& Davies, 2015; Gaberdan, et al., 2014; Chew, et al., 2014; Valkering, et al., 2013; Rusca, et al., 2012), flood risk management (Douven, et al., 2014; Stefanska, et al., 2011; Rijcken \& Christopher, 2013), river management and climate adaptation pathways (Valkering, et al., 2013; Van der Wal, et al., 2016), water pollution (D'Artista \& Hellweger, 2007), water supply (Rijcken \& Christopher, 2013; Bassi, et al., 2015), irrigation (Seibert \& Vis, 2012), etc.. 
This paper presents the use of serious gaming to solve pipe-sizing problems related to different benchmark WDNs, where players/decision-makers are 26 students of a master class in Hydraulic Engineering. Each player worked individually, without comparing results with other colleagues.

\section{The teaching experiments}

The proposed Serious Game is conceived for WDNs sizing/rehabilitation and is named Network Pipe Sizing (NPS). It allows changing diameters (size) in the network, returning nodal pressure in each node and capital cost of the solution. The game implements a pressure-driven hydraulic simulation model, including a background leakage model (not for all the levels), and is based on the software tool WDNetXL (Giustolisi, et al., 2011). The network size (and complexity) increases at each "level" of the game, requiring that players adapt to different situations and constraints, e.g. size of the network, network layout, number of reservoirs, etc., to build new strategies to get the final goal. The game purpose is to achieve the least-cost pipe sizing solution at minimum average pressure, without pressure deficient nodes.

From the teaching point of view, this can be useful to understand the importance of the elements (pipes) of the networks in terms of diameters (pipe sizing) to find solutions near to the optimum. An additional aim is to verify if the gaming approach is useful to consolidate or learn the main concepts of WDNs hydraulics.

From the decision-making point of view, the exercise aims to bring users closer to real-life sizing/rehabilitation problems where different technical aspects must be considered at the same time, such as asset characteristics, specific technical purposes (e.g., rehabilitation), pressure (e.g. avoiding pressure deficient conditions), and budget constraints (cost).

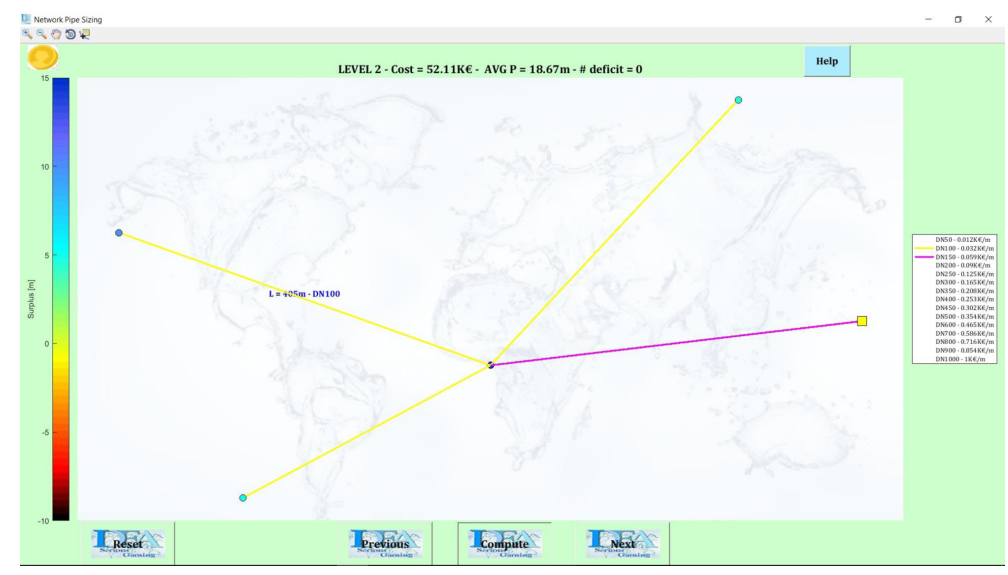

Figure 2. Second level of the NPS Game for WDNs sizing/rehabilitation.

Figure 2 shows the game interface of the second level (the first level is very simple, i.e. a single pipe fed by a reservoir), and reports its optimal solution. The game has a friendly graphical interface, as confirmed by the students, who found the game very intuitive. Yellow squares represent reservoirs and circles represent nodes, where the colour ramp on the left, from black to blue, indicates the nodal pressure condition (from pressure deficient condition to a regular one). Fifteen diameter classes are available in this version. 
To select a diameter for each pipe, the user has to press the right button of the mouse and simply choose from the menu. Once selected, a label (e.g. DN150) and a colour (see window on the right in Figure 2) indicate the diameter, to help in identifying each diameter, especially for more complex networks (see Figure 4, for example). If there are no pressure deficient nodes, NPS allows the user to go to the next level getting a coin, no matter about the total pipe cost. If the user has already a coin, he/she can use it, to pass to the next level with some nodal deficit in the WDN but losing the coin.

The sum of the network costs is the overall score of the game for each student. Obviously, the competition forces the students to try to minimize the total cost of the networks/levels faced, and then forces them to look for the best combination of diameters.

The teaching experiment here presented involved 26 students of a master class in Hydraulic Engineering of the Technical University of Bari (Italy), providing just the first five levels of NPS game, which implement benchmark networks.

The solution of the first two (simplest) levels (see Figure 2 for the second level) are not considered for the discussion of results, but rather as an initiation to the game and its features (i.e. a sort of training). Therefore, results for the third, fourth and fifth levels are briefly reported and discussed.

Please note that they both refer to an optimal solution used as reference point for the considerations reported. The target cost of these optimal solutions was not provided to the participants before the competition, thus students have operated without having any clear target, as generally happens for all the video games.

Furthermore, the students were explicitly told that for the evaluation of results, the average pressure in the network (i.e. AVG P in the upper part of Figure 2) would not be considered. Consequently, everyone decided to achieve pressure minimization, given that the NPS game gives the possibility to proceed with successive levels provided that the pressure deficits are absent.

\subsection{Level 3: Gessler}

Figure 3 shows the optimal solution for the Gessler network used for this experiment. The network consists of 2 reservoirs, 14 pipes and 12 nodes. This network is quite simple, but the presence of two reservoirs, from the design standpoint, can represent a difficulty for students.

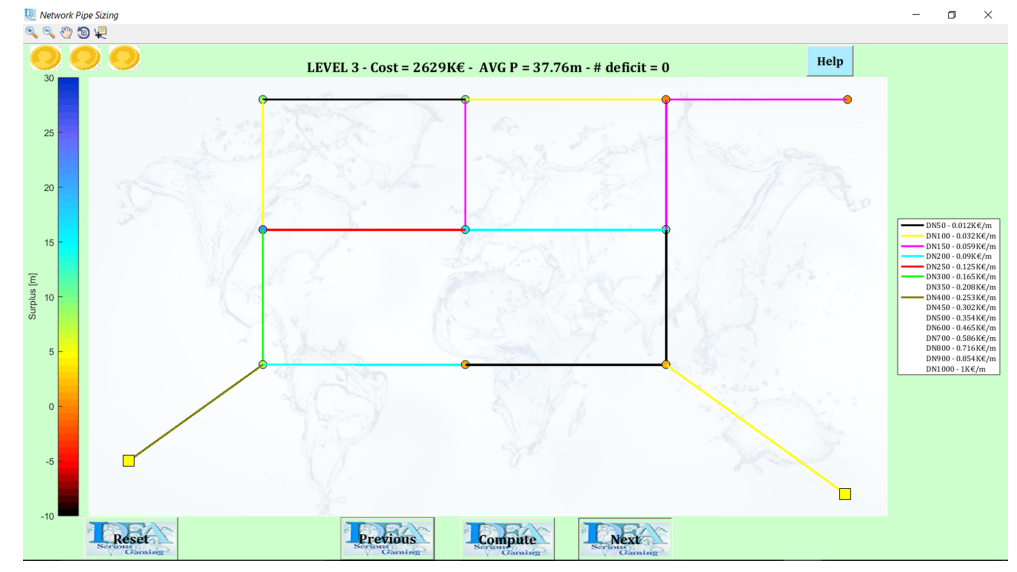

Figure 3. Optimal solution of Gessler network on the game NPS

Figure 4 reports a diagram summarizing the results of the sizing experiment/game as performed by the students, showing the cost of the WDNs designed by the students normalized to the cost of the optimal solution. Therefore, the optimal solution is identified by the value 1 , while the solutions of the students are all greater than 1 ; in this way it is possible to evaluate the percentage difference from the 
best solution (target). Please note that for reasons of privacy, the names of the students have been replaced with numbers, which along with the whole discussion will always refer to the same student.

Observing Figure 4, there were not many students who get very close (below 10\%) to the target, and in general most of them are between $15 \%$ and $25 \%$. Even if, before the competition, it was declared that average pressure minimization was not a target, it could be interesting to analyse the behaviour of the students with respect to pressures. Therefore, it is possible to notice that the average value of the average network pressures (AVG P) obtained by the students was $38.6 \mathrm{~m}$, with a standard deviation of $3 \mathrm{~m}$. From the interviews conducted with the students after the experiment, it emerged that the average pressure has been taken in great consideration, sometimes even at the expense of the pipes cost. This can indicate a higher sensibility of students to adequately supply water to customers, than the economic aspect of the service.

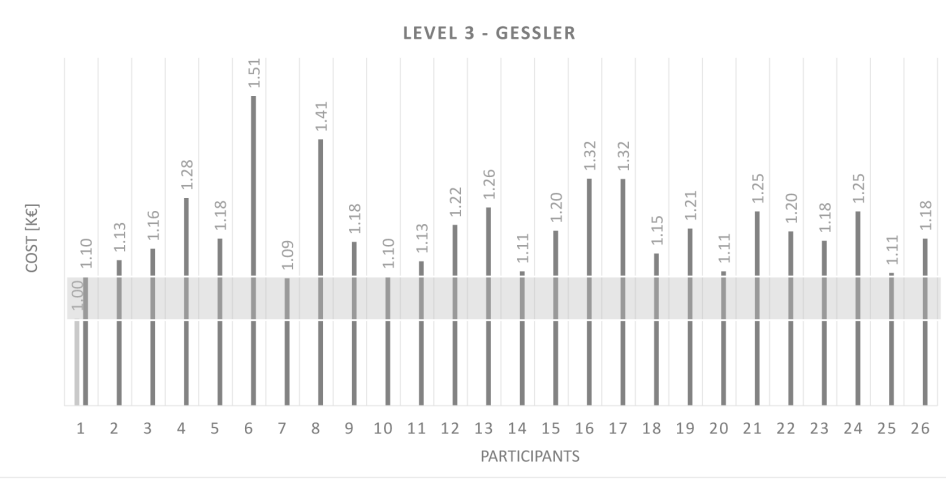

Figure 4. Third Level: Results obtained by students as normalized values with respect to the optimal solution.

\subsection{Level 4: Hanoi}

The Hanoi network is composed by 1 reservoir, 35 pipes and 28 nodes, and its optimal solution is reported in Figure 5. In this level, many the available diameters were used to reach the optimal solution (13 out of 15). The singularity of this network is the presence of many serial nodes, i.e. nodes that have only one inlet pipe and only one outlet pipe. This could cause difficulties for students, also because they did not know the nodal demands and elevations.

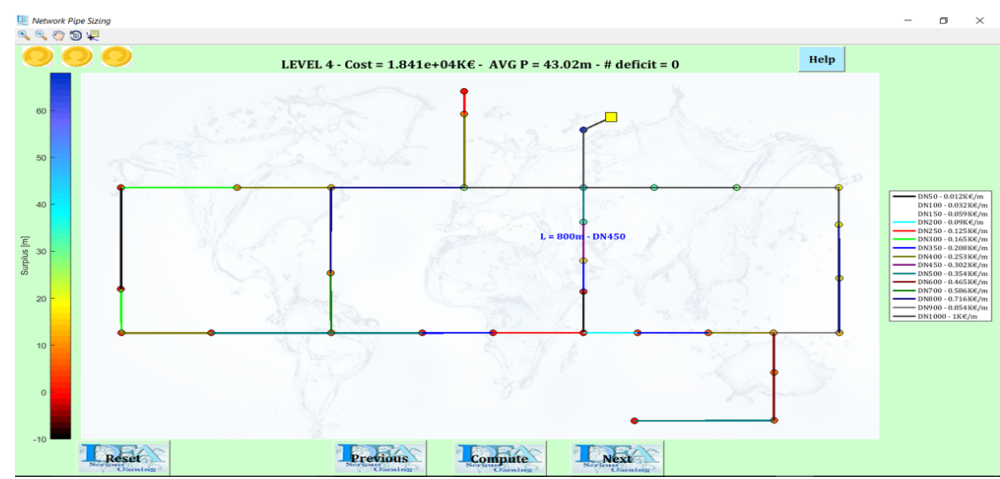

Figure 5. Optimal solution of Hanoi network on the game NPS. 
More than for Gessler, in this level only one student managed to stay within $10 \%$ of difference from the cost of the optimal solution, while the majority was almost between $20 \%$ and $30 \%$. Moreover, clearly, three students were happy with their first-try solution, without adding further efforts, but obtaining 50\% more costs than the optimal solution. This evidence confirms the difficulties of designing a network having several serial nodes.

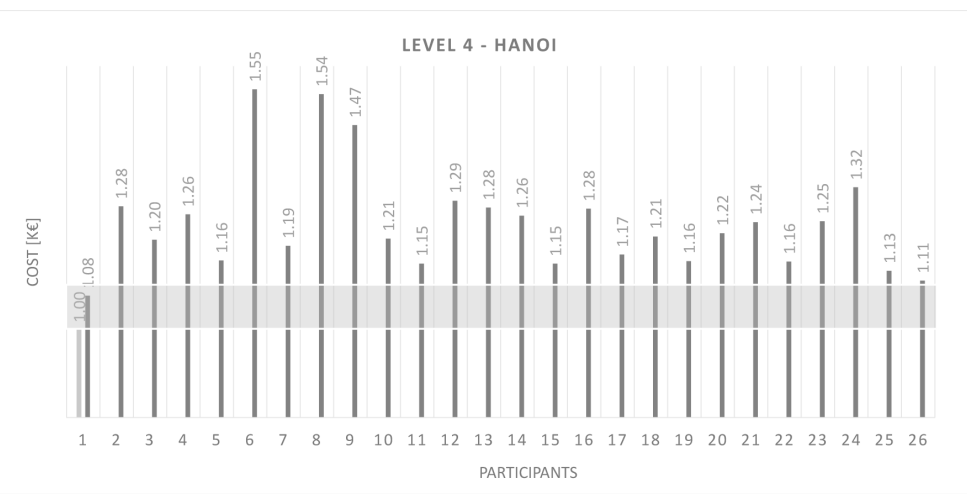

Figure 6. Fourth level: Results obtained by students as normalized values with respect to the optimal solution.

Finally, considering the behaviour of students with respect to pressures, the average value of the average network pressures (AVG P) obtained by the students was $43.8 \mathrm{~m}$, with a standard deviation of $4.4 \mathrm{~m}$. This figure, beyond the three outliners mentioned above, confirms the tendency to prefer the lowering of the average pressure even at the expense of the network cost.

\subsection{Level 5: Apulian}

Figure 7 reports the optimal solution for Apulian network, the last level considered in the experiment. This network has 1 reservoir, 34 pipes and 23 nodes and, differently from the previous levels, includes a leakage model defined as in WDNetXL (Giustolisi, et al., 2011). This network is more meshed than the previous and presents some difficulties in sizing because the presence of the leakage model, a demand component that does not refer to the service pressure (observable indirectly by the students through the assessment of pressure deficits) and can create confusion in the knowledge acquired through the previous levels.

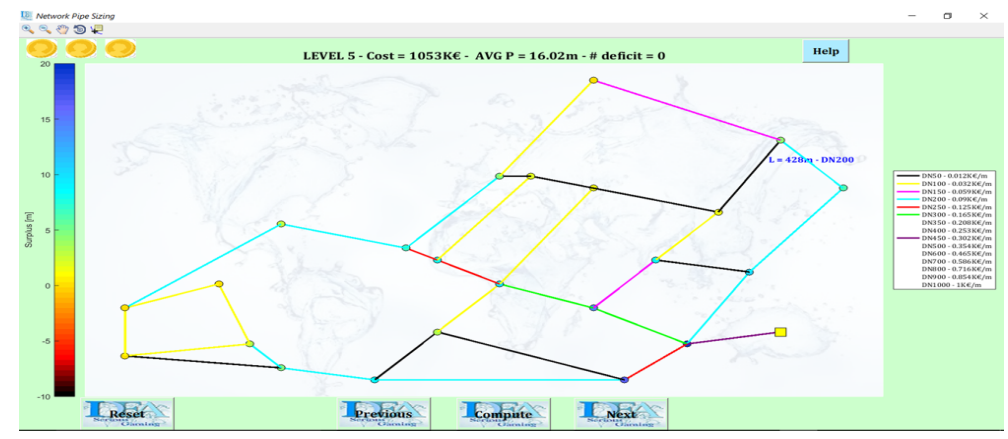

Figure 7. Optimal solution screenshot of the fifth level of the NPS Game for WDNs rehabilitation 
The practice in the game or the right strategy resulted in one of the students getting a solution very close to the optimal one, while the majority is almost between $20 \%$ and $50 \%$, confirming the difficulty of this network. There are 2 students that held the solution on the first attempt, clearly oversizing the network. The presence of the leakage model in Apulian network likely represented a disturbing factor with respect to the concept, acquired in the previous levels, of the consequentiality between decrease in diameter (and therefore the cost) and decrease of the average pressure (or the deficit onset).

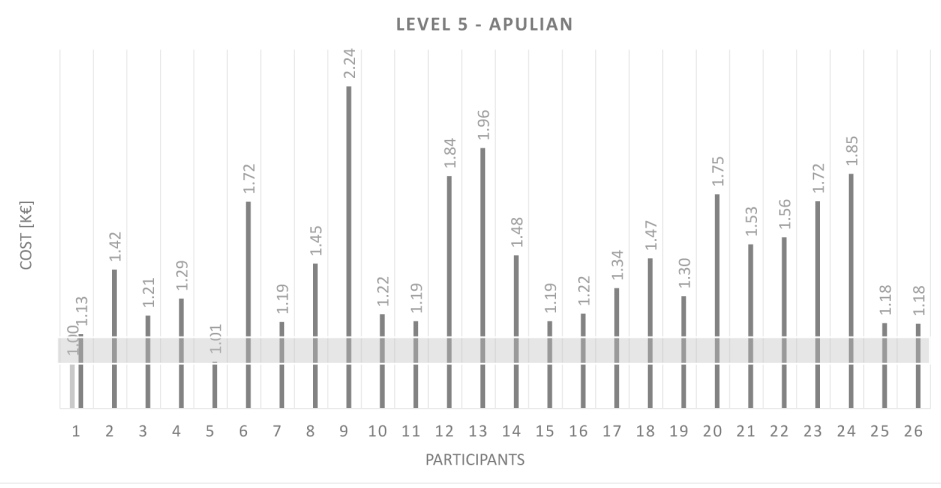

Figure 8. Fifth level: Results obtained by students as normalized values with respect to the optimal solution

Finally, considering the behaviour of students with respect to pressures, the average value of the average network pressures (AVG P) obtained was $16.7 \mathrm{~m}$, with a standard deviation of $1.8 \mathrm{~m}$. For this level, it can be said that the students obtained very similar solutions in terms of configuration of diameters, compared to the previous levels. From the interviews conducted with the students after the experiment, resulted that concepts related to the leakage model and the WDNs network operation have become clearer than before, highlighting the fact that every part of the network is linked to others and the network needs to be considered as a whole.

\section{Discussion of results}

A final questionnaire helped post-game considerations, as well as the final discussion in the classroom. This way, participants had the opportunity to highlight negative aspects of the tool (NPS), as well as both practical and theoretical difficulties, acquired knowledge and awareness gaining with respect to the background theory. The discussion was driven by the teachers (i.e. the authors) analysing each level, focusing on the hydraulic aspects of the networks that each level has allowed to deepen. The contribution of each student to the discussion was free, and most of them contributed by reporting their impressions and suggestions. All the students participated in the discussion. As general impression, the students underlined how the approach to design of the network by means of NPS was much simpler and more intuitive than what was done in other courses of study, where they faced it with traditional methods and supports (books, tables, calculators, etc.). From classroom discussion, for most students, the choice of using a strategy to get the solutions has been the basis for the solution of the various levels, realizing that a balanced network is synonymous of a well-designed WDN. The strategies have been adopted also considering the diversity of each examined level, as for example inserting large diameters near the reservoirs and gradually descending towards the ends of the network, or for redundant networks (e.g., Apulian) they felt the need to close links to better control higher pressures. In real life they would need 
valves to be closed, but since this is not possible in NPS, many have opted for the insertion of small diameters to simulate the closure of the links.

For the sake of teaching network hydraulics and basics of network management, this need felt by the students was useful to introduce and fix concepts as the need of network segmentation to improve the ability in managing higher pressures both from an operative point of view (open/close valves) and from a modelling standpoint (i.e. the difference between having a small diameter link or a valve). The discussion helped students to understand that some aspects of network behaviour are not always and imperatively valid in each situation, and that much depends on the type of network analysed.

\section{Conclusions}

The presented experiment confirmed that game-based learning is a valid tool. Most students found this approach useful, confirming that the trial\&error strategy helped consolidating concepts related to the functioning of WDNs as well as the possibility of analysing different typologies. They also increase awareness about the need for optimization strategies in solving such complex technical problem. The main advantage is the fact that the problem facing can be carried out even without detailed knowledge of hydraulics and boundary conditions of networks. This way, through a trial\&error procedure, it is possible to get a solution that is very close to the optimal one. The level of difficulty for non-expert users in dealing with WDNs sizing problems decreases considerably and tends to zero as the practice of the game increases.

\section{Reference}

Abt, C., 1970. Serious Games; . New York, NY, USA: Viking.

Bassi, A., de Rego, F., Harrisson, J. \& Lombardi, N., 2015. WATERSTORY ILE: A Systemic Approach to Solve a Long-Lasting and Far-Reaching Problem. Simul. Gaming, Volume 46, pp. 404429.

Brown, S., Lieberman, D., Gemeny, B. \& Fan, Y., 1997. Educational video game for juvenile diabetes: results of a controlled trial. Informatics for Health \& Social Care, Volume 22, pp. 77-89.

Chew, C. et al., 2014. A Serious Gaming Approach for Serious Stakeholder Participation. New York, USA, Proceedings of the XI International Conference on Hydroinformatics.

D’Artista, B. \& Hellweger, F., 2007. Urban hydrology in a computer game?. Environ. Model. \& Softw., Volume 22, pp. 1679-1684.

de Freitas, S., 2006. Using games and simulations for supporting learning. Learning, Media and Technology, Volume 31, pp. 343-358.

Douven, W. et al., 2014. Games to create awareness and design policies for transboundary cooperation in river basins: Lessons from the shariva game of the Mekong river commission. Water Resour. Manag., Volume 28, pp. 1431-1447.

Gaberdan, E., Maier, K., Söbke, H. \& Londong, J., 2014. Illustrating decisions to end-users: The case of agent-based simulation for stormwater management. Stuttgart, Proceedings of the Computational Methods in Water Resources 2014 XX. International Conference.

Giustolisi, O., Savic, D., Berardi, L. \& Laucelli, D., 2011. An Excel-based solution to bring water distribution network analysis closer to users. Proceedings of Computer and Control in Water Industry, Volume 3, pp. 805-810.

Graham, B., 1996. Serious games: Art, interaction, technology. s.l.:Barbican Art Gallery in association with Tyne \& Wear Museums. 
Harfield, M., 2008. Not Dark Yet: A Very Funny Book About a Very Serious Game. s.1.:Loose Chippings Books.

Jansiewicz, D., 1973. The New Alexandria Simulation: A Serious Game of State and Local Politics. s.l.:Canfield Press.

Jansiewicz, D., 2011. The Game of Politics - Frequently Asked Questions, s.1.: s.n.

Kahn, M. \& Perez, K., 2009. The Game of Politics Simulation: An Exploratory Study. Journal of Political Science Education, Volume 5, pp. 332-349.

Leroy, E. \& Saulnier, G., 2013. Serious-game for water resources management adaptation training to climatic changes, EGU General Assembly. Vienna, s.n.

Morley, M., Khoury, M. \& Savic, D., 2017. Serious Game Approach to Water Distribution System Design and Rehabilitation Problems. Procedia Engineering, Volume 186, pp. 76-83.

Rijcken, T. \& Christopher, D., 2013. SimDelta global: Towards a standardised interactive model for water infrastructure development. Eur. J. of Geografy, Volume 4, pp. 6-21.

Rusca, M., Heun, J. \& Schwartz, K., 2012. Water management simulation games and the construction of knowledge. Hydrol. Earth Syst. Sci., Volume 16, pp. 2749-2757.

Sawyer, B. \& Rejeski, D., 2002. Serious Games: Improving Public Policy Through Game-based Learning and Simulation, s.1.: Woodrow Wilson International Center for Scholars.

Schrage, M., 1999. Serious Play: How the World's Best Companies Simulate to Innovate. 1 ed. s.1.:Harvard Business Press.

Seibert, J. \& Vis, M., 2012. Irrigania - A web-based game about sharing water resources. Hydrol. Earth Syst. Sci., Volume 16, pp. 2523-2530.

Stefanska, J. et al., 2011. A Gaming Exercise to Explore Problem-Solving versus Relational Activities for River Floodplain Management. Environ. Policy Gov., Volume 21, pp. 454-471.

Valkering, P. et al., 2013. Perspective-based simulation game to explore future pathways of a watersociety system under climate change. Simul. Gaming, Volume 44, pp. 366-390.

Van der Wal, M. et al., 2016. Can computer models be used for social learning? A serious game in water management. Environ. Model. \& Softw., Volume 75, pp. 119-132.

Wang, K. \& Davies, E., 2015. A water resources simulation gaming model for the Invitational Drought Tournament. J. Environ. Management, Volume 160, pp. 167-183. 